\title{
A TEORIA DE JOHN LOCKE E O DIREITO BRASILEIRO: UM PARALELO PARA A FUNÇÃO SOCIAL DA PROPRIEDADE
}

\author{
Carlos André Maciel Pinheiro Pereira ${ }^{39}$ \\ Renata Emanuele de Araújo Nogueira 40 \\ Stephane Melissa de Souza Dantas ${ }^{41}$
}

Recebido em: 24/12/2018

Aprovado em: 26/02/2019

\begin{abstract}
RESUMO
A propriedade, como forma de direito, é parte de um processo histórico de construção e para o jusnaturalista John Locke, a propriedade pode ser visualizada como um direito natural de origem divina que não pode ser violado. Tal direito conta, atualmente, com restrições e é amparado como sendo direito fundamental na ordem constitucional, bem como a sua função social garantida na Constituição Federal. Esse estudo apresenta a propriedade privada sob a ótica de Jonh Lock, ponderando o seu entendimento com o direito protegido no ordenamento jurídico, especialmente no que conserne à função social legitimada por eles. As análises do trabalho foram desenvolvidas a partir da metodologia de pesquisa qualitativa exploratória, comparando teorias com documentos legais e utilizando o método indutivo. Entende que a teoria de Locke e o ordenamento jurídico brasileiro apresentam semelhança quanto ao direito de uso da propriedade, para Locke a propriedade deve ser legitimada pelo trabalho do homem, tendo produtividade e não lesando o coletivo, prescrito no ordenamento como atendendo a função social. Ao final, conclui que as ideias amparadas por Locke fazem parte de uma evolução histórica que auxiliou a difusão dos estudos que a propriedade é um direito inerente ao homem e que deve ser protegida pelo Estado, pois a ordem jurídica brasileira reconhece a propriedade, sua função social e importância.
\end{abstract}

Palavras-chave: John Locke. Estado civil. Direito à propriedade. Função social da propriedade.

\section{INTRODUÇÃO}

\footnotetext{
${ }^{39}$ Mestre em Direito Constitucional pela Universidade Federal do Rio Grande do Norte - UFRN. Especialista em Direito Tributário pelo Instituto Brasileiro de Estudos Tributários - IBET. Professor da Escola de Direito da Universidade Potiguar - UnP.

${ }^{40}$ Graduanda em Direito pela Universidade Potiguar - Unp.

${ }^{41}$ Graduanda em Direito pela Universidade Potiguar - Unp.
} 
A propriedade sempre esteve presente na sociedade, se apresentando nas mais diversas teorias de autores filosóficos com conotações que ganharam importância política nos mais distintos momentos históricos. As transformações sociais, econômicas e políticas fizeram com que a atuação e direito a propriedade sofresse várias mudanças, mudaram-se os princípios surgindo paradigmas legais como forma de regulamentá-la.

Uma das garantias fundamentais resguardadas pela Constituição Federal, a propriedade, teve como um de seus principais defensores na modernidade, o filósofo contratualista John Locke. Em sua obra "Segundo Tratado Sobre o Governo Civil", fez sustentação da importância da propriedade, defendendo-a como um direito natural, além disso, o jusnaturalista traz questionamentos sobre o uso, a legitimidade da propriedade e atuação do Estado na sua proteção. Para a ordem jurídica brasileira, a normatização tem buscado visar os fins sociais a que se destina, e o interesse estatal em sua preservação, assemelhando-se bastante com os estudos de John Locke.

Este estudo tem como objetivo apresentar a teoria de Jonh Lock sobre a propriedade analisando a sua consonância com o direito resguardado no ordenamento jurídico brasileiro, com destaque na função social adotada por eles.

A metodologia apresentada será a pesquisa qualitativa exploratória, comparando teorias com documentos legais, utilizando o método indutivo partindo de um objeto específico para uma construção mais generalista.

As referências que serão empregadas são baseadas em pesquisas bibliográficas da teoria de Locke, obras de Filosofia Política, autores de Direito Civil e Constitucional com o intuito que as informações possuam conexões entre cada um dos tópicos.

No primeiro tópico subsequente, a teoria de Jonh Locke será disposta trazendo a sua ideia de Estado de Natureza e o seu modelo do Estado Civil, contextualizando como deve ser a atuação Estatal. Enquanto que, na segunda etapa, irá tratar do direito à propriedade defendido por Locke e sua importância e proteção. Na terceira seção, será abordado o direito à propriedade regulamentado pelo ordenamento brasileiro, com suas respectiva importância, proteção, função e poder, como também, em qual parte pode ser encontrado. Por fim, no último tópico desse estudo, será abordado, de forma específica, acerca da função social da propriedade no sistema constitucional, correlacionando com a teoria defendida por John Locke. 


\section{LINHAS GERAIS SOBRE A TEORIA DE JOHN LOCKE E O MODELO DO ESTADO CIVIL}

John Locke traz na sua obra um grande avanço para a autonomia política, considerado como o pai do liberalismo político, provoca ideias que modificaram a visão política no tempo, uma vez que acredita que o conhecimento humano é fruto de experiências. Afastando assim a ideia de que o conhecimento constitui algo inato aos indivíduos. (BITTAR, 2005, p. 176)

Originando a ideia de estado de natureza como uma análise da construção histórica do estado, John Locke não o caracteriza como bélico da maneira que fez Thomas Hobbes. Em Hobbes, se apresenta uma situação de conflito entre fortes e fracos, tanto que para cessar o impasse, os indivíduos se decidem por se sucederem ao Estado Civil, isto é, cria-se o Estado com poder político e leis

Para tanto, o estado civil de John Locke é conduzido pelo aperfeiçoamento do estado de natureza, já que no segundo os homens viviam não obedecendo a nenhuma outra lei a não ser a natural, assim o estado ideal vem para que se tenha a organização estatal necessária, além de colocar os princípios fundamentais da lei da razão (BITTAR, 2005, p. 179).

Locke aponta uma possível confusão entre o estado de natureza com o estado de guerra, sendo que, no estado de natureza, o homem vive na lei da natureza, sendo governado para viver na sua atual situação, já no estado de guerra o homem vive sem uma autoridade para regulamentar as relações. Com isso, surge o pensamento do "direito" de cada indivíduo de fazer vingança por meio da violência, tal qual seria essencial para a formação e manutenção do estado de guerra.

Sendo duas as distinções do estado de natureza para o estado de guerra: a ausência de um juiz para todos que vivem na lei da razão e a necessidade das pessoas de aglomerarem e formarem sociedade com o objetivo de acabar com o estado de guerra e, assim, formar um estado que vai regulamentar as condutas, sendo os indivíduos submetidos agora a uma autoridade comum que vai solucionar os conflitos de maneira mais harmônica e seguindo as lei (BITTAR, 2005, p. 180).

A partir disso, a sociedade civil surge quando o homem precisa de autoridade para regulamentar as relações de convívio dos indivíduos, tendo agora leis com sanções e penas para os indivíduos que cometem irregularidades que devem ser obedecidas, como também, autoridades responsáveis pela sua manutenção e execução, tendo como objetivo a conservação da propriedade privada (WEFFORT, 2001, p. 96). Contudo, apesar de não defender o Estado de guerra, havia uma arbitrariedade individual, sendo um motivo para se 
buscar um Estado civil. A outra razão, sendo para Locke a principal, estaria associada a propriedade, uma vez que sem o Estado não haveria condição de segurança para preservar tal direito natural.

A organização estatal deve acontecer, independentemente da forma de governo, em três poderes que foram baseados no Estado Inglês: o legislativo - poder soberano em relação aos demais -, o executivo - confiado ao príncipe - e o poder federativo - responsável pelas relações exteriores -, devendo respeitar a hierarquia de poder para a manutenção do estado já que ninguém é submetido a qualquer outro poder ou autoridade a não ser o da lei (BITTAR, 2005 , p. 185). Locke expõe que quando os poderes não cumprem a lei de maneira correta funda-se uma tirania, uma vez que violou- se o direito público e do bem comum (WEFFORT, 2001, p. 87).

Os cidadãos, então, podem depor o tirano - direito à resistência - para evitar o surgimento de conflitos com o governo que acarretariam no estado de guerra e a quebra da sociedade civil, sendo que é pelo consentimento da população que se decide as formas de gerir a sociedade e, somente pelo consenso da sociedade civil, é que ocorre a deliberação da ilegitimidade do abuso de Poder Legislativo, todo poder emana da sociedade já que os indivíduos a formaram. (BITTAR, 2005, p. 188)

Locke tem como princípio que o Estado deve regulamentar as relações externas dos indivíduos relacionadas à convivência social, contudo, não pode ter autonomia em direitos resguardados pelos indivíduos como os direitos inerentes a personalidade humana e que antecedem mesmo o Estado de natureza, como a vida. (MALUF, 2013, p. 72). O contrato social ocorre se os indivíduos compactuarem, tendo em vista que o governo é uma troca de serviços com a população. Entende-se, então, que a ideia da transição do estado de natureza para o estado civil, independente da forma de governo, estariam fincadas para preservar e conservar as propriedades e as comunidades de conflitos internos e externos, prevalecendo a soberania popular.

Toda a construção do autor em torno do governo civil tem como finalidade a conservação da propriedade - um direito inato aos homens - com leis e autoridades que conservem os direitos e cidadãos para a convivência harmônica e pacifica (BITTAR, 2005, p. 185). A legitimação que Locke oferece para a propriedade privada é dada por explicação divina, ou seja, Deus quem deu a terra aos filhos dos homens, assim, a toda a humanidade, para o sustento e conforto da existência. À vista disso, se compreende que o meio natural pertence em comum a todos os indivíduos, contudo, cada um guarda sua própria 
propriedade, no qual, Locke diz que a caracterização da propriedade privada se dá pelo trabalho que se aplica nela. (LOCKE, 1994, p. 42)

Com isso, John Locke destaca-se pela sua ideia de propriedade privada como legítima inserida na sua teoria social e política. Para o filósofo, o direito de propriedade é a base da liberdade humana, isso por que todo homem tem a sua propriedade como sua casa, tendo em vista que o homem emprega uma dedicação para tê-la. Logo, o governo existe para proteger esse direito de possíveis violações.

\section{DO ESTADO CIVIL AO DIREITO DE PROPRIEDADE}

John Locke, como jusnaturalista expõem os direitos e os princípios como algo universal, para todos, e que isso independe da vontade humana. O direito a comer, a beber e a todas as outras coisas que a natureza proporciona para a sobrevivência é a razão natural e, segundo ele, foi Deus quem deu a terra aos filhos dos homens, assim, a toda a humanidade, para o sustento e conforto da existência. A partir disso, se compreende que o meio natural pertence em comum a todos os indivíduos, contudo, cada um guarda sua própria propriedade, que no qual se caracteriza em propriedade privada pelo trabalho que se aplica nela (LOCKE, 1994, p. 42).

Entende-se que o trabalho determina a separação entre o comum e o privado, além disso, não é necessário o consentimento de todos que estão envolvidos no meio comum, Locke dá um exemplo por meio da água de uma fonte e afirma que, ainda que a água que corre na fonte pertença a todo mundo, quem duvida que no cântaro ela pertence apenas a quem a tirou? Seu trabalho a tirou das mãos da natureza, fazendo dela sua propriedade. A partir disso, infere-se que a dedicação para a remoção do estado comum em que se encontravam, fixa o direito de propriedade sobre eles, uma vez que se admite que o objeto pertence àquele que lhe consagrou seu trabalho (LOCKE, 1994, p. 43).

Entretanto, não pode o homem tomar tudo para si devendo ter tanto quanto pode utilizar, se ultrapassar o limite que lhe é necessário, aquilo deixa de ser sua propriedade e passa a ser, novamente, do bem comum, pois significaria que ele havia colhido mais que a sua parte e, portanto, roubado dos outros ou seja seu direito acaba com a necessidade de utilizar estes bens (LOCKE, 1994, p. 44). Contudo, se, antes o alimento estragar, da terra ficar inculta ou a água imprópria, o indivíduo tivesse trocado suas frutas que iriam perecer em uma semana, por sementes que durariam um ano para serem comidas, não estaria lesando 
ninguém e nem desperdiçando a reserva comum, ao passo que nada se estragaria de forma inútil consigo. $\mathrm{O}$ mesmo ocorre com o dinheiro, diamantes ou demais pedras preciosas, ao trocar seu alimento que ia apodrecer por outras coisas mais duradouras, em nada estaria ferindo o direito do outro. Assim, o fato de poderem guardar a quantidade que quisessem não excederia seu limite, pois de qualquer forma, não iriam se deteriorar (LOCKE, 1994, p. 48). Sendo o direito de propriedade algo inato e natural ao homem e, cabendo, ao governo a proteção desse direito, é estabelecida uma renúncia parcial dos direitos individuais para o Estado atuar em serviço dos cidadãos, intitulado contrato social.

O contrato social é o mecanismo que indica a mudança do estado de natureza, que possui uma insegurança generalizada, para a sociedade civil. Essa sociedade civil nasce com o objetivo de, justamente, propiciar a proteção da propriedade e da comunidade dos perigos internos e externos. Ademais, a própria existência de um direito de propriedade corrobora com a importância do Estado, eis que a garantia daquele direito depende de instituições públicas aptas a tutelar os conflitos que dele advém. (DIMOULIS, MARTINS, 2014, p. 76) Logo, aqui se revela a relação existente entre a propriedade e sociedade civil, que se origina como forma protetiva da sociedade, sendo que a forma de governo da sociedade civil tem que ocorrer pelo consentimento das maiorias.

\section{O DIREITO A PROPRIEDADE NO ORDENAMENTO BRASILEIRO}

A propriedade sempre foi assunto de questionamento no tocante a sua funcionalização como direito, de maneira que possa alcançar as mais diferentes manifestações proprietárias que existem e as diversas formas de atuação dos indivíduos sobre as coisas. Não obstante, trazida para o direito contemporâneo, a proposta de Locke quanto aos postulados liberais pode ser configurada uma garantia constitucional mínima ao exercício da liberdade, em especial nas intervenções estatais sobre questões econômicas, à exemplo da propriedade. (DIMOULIS, MARTINS, 2014, p. 27).

É importante definir a propriedade pela sua natureza jurídica que pode se tomar um fato social, um direito subjetivo e uma função, sendo conceituada como uma relação jurídica complexa formada entre o titular do bem e a coletividade de pessoas. (FARIAS; ROSENVALD, 2015, p. 215 - 217). Afinal, trata-se de um direito de previsão constitucional e que necessita de uma regulamentação infraconstitucional, dada pelo Código Civil, para ser verdadeiramente exercido. (DIMOULIS, MARTINS, 2014, p. 47) 
O direito à propriedade é um dos direitos mais amplos da pessoa em relação as coisas, ficando submetida ao titular, ao dominus, ao proprietário. $\mathrm{O}$ seu poder é descrito no art. 1.228 do Código Civil: "O proprietário tem a faculdade de usar, gozar e dispor da coisa, e o direito de reavê-la do poder de quem quer que injustamente a possua ou detenha" (VENOSA, 2017, p. 183). O primeiro elemento constitutivo da propriedade é o direito de usar (jus utendi), que consiste na faculdade de o dono servir-se da coisa e de utilizá-la da maneira que entender mais conveniente, sem, no entanto, modificar a sua substância, podendo excluir terceiros de igual uso. A utilização porém deve ser feita, dentro dos limites legais e de acordo com a função social da propriedade. Preceitua a propósito o $\S 1^{\circ}$ do mesmo art. 1.228 do Código Civil que "o direito de propriedade deve ser exercido em consonância com as suas finalidades econômicas e sociais...”. A faculdade em apreço permite também que o proprietário deixe de usar a coisa, mantendo a simplesmente inerte em seu poder, em condições de servi-lo quando lhe for conveniente. O direito de gozar ou usufruir (jus fruendi) compreende o poder de perceber os frutos naturais e civis da coisa e de aproveitar economicamente todos os seus produtos (GONÇALVES, 2017, p. 242-243)

O direito de dispor da coisa (jus abutendi) consiste no poder de transferir a coisa, de gravá-la de ônus e de aliená-la a outrem a qualquer título. Não significa, todavia, direito de abusar da coisa, destruindo-a gratuitamente, pois a própria Constituição Federal prescreve que o uso da propriedade deve ser condicionado ao bem-estar social. Nem sempre, portanto, é lícito o proprietário destruir a coisa que lhe pertence, mas somente quando não caracterizar um ato antissocial, já que o $\S 2^{\circ}$ do art. 1.228 do Código Civil dispõe que: "São defesos os atos que não traze ao proprietário qualquer comodidade, ou utilidade, e sejam animados pela intenção de prejudicar outrem". O quarto elemento constitutivo é o direito de reaver a coisa (rei vindicatio), de reivindicá-la das mãos de quem injustamente a possua ou detenha, como corolário de seu direito de sequela, que é uma das características do direito real. Envolve a proteção específica da propriedade, que se perfaz pela ação reivindicatória. (GONÇALVES, 2017, p. 243)

Trata-se dos mais completos dos direitos subjetivos patrimoniais no qual o titular exercita poder de dominação sobre um objeto, pois quando uma pessoa estiver aludidos todos os elementos constitutivos, será titular da propriedade plena, se no entanto aos elementos forem exercidos por outras pessoas, diz-se que a propriedade é limitada. (GONÇALVES, 2017, p. 394-395).

Porém o direito à propriedade não fica restrito ao Código Civil, a Constituição Federal prescreve o direito à propriedade como fundamental no art. 5: "Todos são iguais 
perante a lei, sem distinção de qualquer natureza, garantindo-se aos brasileiros e aos estrangeiros residentes no País a inviolabilidade do direito à vida, à liberdade, à igualdade, à segurança e à propriedade...”. O conteúdo constitucional de propriedade abrange em seu manto bens corpóreos e incorpóreos presente nos art. 5, XXVII, XXVIII e XXIX que podem constituir objeto do direito, desde que redutíveis a dinheiro. Em qualquer caso nos termos do art. $5^{\circ}$, XXII, da Constituição Federal a propriedade é tratada como um direito fundamental sendo constitucionalmente tutelada pela sua funcionalidade que revela o adimplemento de sua função social presente no art. 5, XXIII (FARIAS; ROSENVALD, 2015, p. 222). A ideia central do artigo é proteger o direito individual de propriedade e propiciar o direito social fundamental à propriedade, conciliando a defesa da liberdade daquele que é de proprietário com a promoção do princípio da igualdade substancial pela via de sua democratização em prol dos não proprietários (FARIAS; ROSENVALD, 2015, p. 239).

Como foi dito anteriormente a propriedade é um direito subjetivo, um fato social e função que apresenta titularidade formal e relação jurídica entre proprietário e coletividade, o art. 1.231 do Código Civil dispõe que "a propriedade presume-se plena e exclusiva, até prova em contrário", estabelece-se a presunção em favor do titular. Ela é exclusiva por que a exclusividade é um princípio que se dirige ao domínio, pois não pode haver mais de um domínio sobre o mesmo bem, sendo também ilimitada, subsistindo independentemente do exercício de seu titular, sendo transmitida por direito hereditário aos sucessores, extinguindose somente pela vontade do dono, ou por disposição expressa de lei, nas hipóteses de perecimento da coisa, desapropriação ou usucapião (FARIAS; ROSENVALD, 2015, p. 249251).

Para além de seu reconhecimento constitucional expresso o caráter fundamental do direito de propriedade, são inegáveis a sua imutabilidade formal e material e a judicialidade plena. A primeira propriedade é a existência, o reconhecimento da propriedade como direito humano se prende à sua função de proteção pessoal de seu titular, um bem individual que consiste na garantia da autonomia privada do ser humano e no desenvolvimento de sua personalidade, pois os direitos reais são outorgados a uma pessoa para a realização pessoal da posição de vantagem que exerce sobre a coisa, sendo assim a propriedade uma extensão da personalidade de alguém, pois as propriedade dos indivíduos sempre vão apresentar algo individual e profundo do titular para expressar sua liberdade pessoal e comprometimento, sendo mais do que uma forma de satisfazer as necessidades (FARIAS; ROSENVALD, 2015, p. 231-232). 
Além de direito subjetivo e fundamental, a propriedade é garantia institucional, prestando-se a assegurar bens jurídicos indispensáveis à preservação de certos valores tidos como essenciais em certa ordem jurídica. A propriedade é tutelada porque sem ela não se desenvolve a personalidade. A proteção da liberdade, privacidade, integridade psíquica, por si, já justifica a permanência da propriedade como instituição, direitos subjetivos, afinal, "a vida, a possibilidade de ir e vir, a manifestação de opinião e a possibilidade de reunião pertencem à natureza do ser humano (FARIAS; ROSENVALD, 2015, p. 233).

O art. 17, a Declaração dos Direitos do Homem prevê que toda pessoa tem direito à propriedade, a dignidade da pessoa humana assume um papel de defesa da integridade humana em dois planos: tutelando as situações jurídicas da personalidade de modo a preservar esses bens jurídicos intrínsecos e essenciais; situando a missão de parte do patrimônio, justamente na preservação das condições materiais mínimas de humanidade, o chamado patrimônio mínimo (FARIAS; ROSENVALD, 2015, p. 236). .

Apresentando todos os indivíduos o mínimo existencial que é visto como algo quantitativa e qualitativamente superior ao mínimo vital, pois é necessária uma postura estatal positiva e ativa de manutenção do mínimo fisiológico e orgânico do ser humano, preservando a vida. Porém, o ser humano possui demandas que não são compartilhadas pelas outras formas de vida na natureza já que a existência não se resume a processos mecânicos, haja vista que a racionalidade e a liberdade nos impelem à felicidade. O homem aspira ir além da mera sobrevivência física e criar sentido para o mundo vivendo com dignidade, além da pobreza. O mínimo existencial atende ao mínimo sociocultural de uma vida saudável com possibilidade de realização de escolhas que atendam ao pleno desenvolvimento da personalidade, o ingresso à saúde básica, o ensino fundamental, assistência social, moradia, cultura e lazer são meios tendentes à promoção da igualdade material, sendo estes direitos fundamentais sociais, sendo interditada qualquer forma de intervenção restritiva por parte do Estado ou de particulares (FARIAS; ROSENVALD, 2015, p. 237-238)

Os direitos sociais presente no artigo $6^{\circ}$ da Constituição Federal são dotados de dimensões positivas e negativas, na esfera positiva demanda prestações estatais jurídicas e materiais, como a garantia do acesso irrestrito à moradia, enquanto na dimensão negativa impede agressões à esfera de liberdade e a outros bens jurídicos fundamentais, através da exigência de um dever de abstenção de comportamentos que possam ofender o bem jurídico tutelado (FARIAS; ROSENVALD, 2015, p. 238). Essas dimensões impõe, simultaneamente, um dever para que o Estado se abstenha de violar a liberdade individual do cidadão - faceta negativa - e também consigna uma obrigação para que a entidade estatal preste as políticas 
públicas necessárias para tutela e concretização daquele direito - dimensão positiva. (DIMOULIS, MARTINS, 2014, p. 50 - 53)

Porém é essencial convir que o conceito deste importantíssimo direito real na coisa própria deverá, necessariamente, levar em conta, sempre, o seu aspecto funcional. Isso porque, nos dias de hoje, a propriedade não é mais considerada um direito ilimitado (GAGLIANO, FILHO, 2017. p. 999). Sendo que a relação função social do direito, pela própria natureza das coisas qualquer direito subjetivo deveria ser direcionado ao princípio da justiça e bem-estar social. Nessa ordem, o Código Civil de 2002 proclama no art. 1.228 , § $1^{\circ}$ que "o direito de propriedade deve ser exercido em consonância com as suas finalidades econômicas e sociais e de modo que sejam preservados, de conformidade com o estabelecido em lei especial, a flora, a fauna, as belezas naturais, o equilíbrio ecológico e o patrimônio histórico e artístico, bem como evitada a poluição do ar e das águas" ; § 2e que "são defesos os atos que não trazem ao proprietário qualquer comodidade, ou utilidade, e sejam animados pela intenção de prejudicar outrem”. (GONÇALVES, 2017, p. 259)

\section{A FUNÇÃO SOCIAL: DA TEORIA DE LOCKE PARA A REALIDADE BRASILEIRA}

John Locke foi pioneiro ao estabelecer limites ao direito de propriedade, concebia a propriedade privada como um conceito central. Para ele, o fundamento da propriedade estava no próprio homem, em sua capacidade de transformar a natureza pelo trabalho. A partir disso, existia um elo entre o fato de subjugar e cultivar a terra e adquirir o domínio sobre ela e, nessa relação, uma garantia o título do outro. (LOCKE, 1994, p. 44)

$\mathrm{O}$ autor relata que a propriedade era limitada pela capacidade de trabalho do homem e pela possibilidade de retirar apenas o suficiente para garantir-lhe o conforto e a sobrevivência, deixando o necessário para a subsistência dos demais indivíduos. Entretanto, caso esses bens viessem a perecer em sua propriedade sem o devido uso; se os frutos apodrecessem ou a caça ficasse putrefata antes de poder ser consumida, ele infringia a lei comum da natureza e era passível de punição: ele estaria invadindo a terra de seu vizinho, pois seu direito cessava com a necessidade de utilizar estes bens e a possibilidade de deles retirar os bens para sua vida (LOCKE, 1994, p. 45)

Como já foi mencionado, tudo o que o homem plantava, colhia, armazenava e consumia antes de se deteriorar pertencia-lhe por direito. Mas se a grama apodrecesse no solo 
de seu cercado ou os frutos de sua plantação perecessem antes de serem colhidos e consumidos, esta parte da terra, não importa se estivesse ou não cercada, podia ser considerada como inculta e podia se tornar posse de qualquer outro, perdendo, assim, o direito à propriedade. (LOCKE, 1994, p. 45). Tais fatos demonstram a preocupação do autor com o interesse coletivo, contudo, é advertido que ninguém pode cercar ou se apropriar de qualquer parcela sem o consentimento de todos os seus coproprietários, que seriam aqueles que a terra permanece comum por convenção, ou seja, pela lei da terra, que não deve ser violada, tendo em vista que a propriedade se estendia até suprir as necessidades da mulher e dos filhos. E embora ela seja comum em relação a alguns homens, isso não ocorre em relação à toda a humanidade; mas constitui a propriedade conjunta deste país ou desta região. (LOCKE, 1994, p. 44)

No que diz respeito a Constituição do Brasil de 1988, de acordo com o art.170, III: “A ordem econômica, fundada na valorização do trabalho humano e na livre iniciativa, tem por fim assegurar a todos existência digna, conforme os ditames da justiça social, observados o princípio da função social da propriedade". Isto é, a função social da propriedade é dita como um direito fundamental e como princípio da ordem econômica. Assume-se, então, um caráter socializante e de interesse coletivo. Como afirmam Dimoulis e Martins (2014, p. 84): "a função social da propriedade não configura um dever do titular, mas um limite constitucional de natureza especial porque permite e impõe ao legislador o dever de concretizá-la".

Pela própria natureza das coisas qualquer direito subjetivo deveria ser direcionado ao princípio da justiça e bem-estar social. Porém, o individualismo exacerbado deturpou de forma tão intensa o sentido do que é direito subjetivo que foi necessária a inserção do princípio da função social nos ordenamentos contemporâneos para o resgate de um valor deliberadamente camuflado pela ideologia então dominante. É fundamental ressaltar que a tutela constitucional da propriedade, alinhada no art. $5^{\circ}$, inciso XXII, é imediatamente seguida pelo inciso XXIII, disciplinando que "a propriedade atenderá a sua função social". Essa ordem de inserção de princípios não é acidental, e sim intencional. Inexiste incompatibilidade entre a propriedade e a função social, mas uma obrigatória relação de complementaridade, como princípios da mesma hierarquia. Não se pode mais conceder proteção à propriedade pelo mero aspecto formal da titularidade em razão do registro. A propriedade que não for legitimada pela função social será sancionada pelo sistema por diversas formas e intensidades. Dessa forma, a função social é inerente, essencial e inseparável do próprio direito de propriedade. (FARIAS; ROSENVALD, 2015, p. 261). 
Neste conspecto, a função social da propriedade vai para além da simples intervenção estatal e se torna um instituto garantidor da isonomia, o que reforça o caráter prestacional do direito à propriedade (BARROS, 2014, p. 57), conforme dito outrorá quando falou-se em dimensão positiva. Três são as consequências da função social para o direito à propriedade: a) a propriedade privada passa a ser pautada pelo interesse social; b) o direito de usar o bem se transforma em uma obrigação, um dever imposto ao proprietário; c) a afetação da titularidade da propriedade de acordo com a finalidade para qual é empregada. (BARROS, 2014, p. 57 58)

Destarte, não se ajusta ao princípio da função social da propriedade a noção da pretensão reivindicatória como "imprescritível", como consequência da perpetuidade do direito subjetivo e impossibilidade de sua perda pelo não uso. Não há justificativa para se tratar ação reivindicatória, de natureza condenatória, de forma diferenciada. Além disso, dentro da ampla relação jurídica estabelecida entre o proprietário e os não proprietários, a pretensão reivindicatória é apenas uma dentre as medidas que o titular pode julgar conveniente para concretizar o direito de excluir terceiros do uso, gozo e disposição do bem. De forma mais ampla, o proprietário pode proibir a colocação de coisas alheias em seu bem imóvel; removê-las, caso não tenha consentido em seu ingresso; também pode impedir que terceiros passem por sua propriedade, para tanto cercando o imóvel (FARIAS; ROSENVALD, 2015, p. 279).

À luz do princípio da função social da propriedade, em uma concepção dinâmica desse direito, a perpetuidade será colocada em xeque quando o titular inerte se exime de emprestar ao bem a sua finalidade normal. De acordo com o art. 187 do Código Civil, o abuso do direito de propriedade é um ato ilícito objetivo que será passível de reprovação pelo ordenamento em diferentes medidas, conforme a intensificação do grau de desprezo à utilidade que a coisa deveria desempenhar. Em certos casos, a verificação do não uso da coisa, associado à lesão à função social, não resultará propriamente na perda do direito subjetivo dito, mas na perda da possibilidade de defendê-la contra terceiros, pois não se pode falar de nascimento de pretensão quando não há lesão a um direito subjetivo que não é exercitado pelo seu titular, da mesma forma que um credor que se olvida em exercitar a pretensão ao crédito. Os direitos nascem para serem exercidos e não apenas conservados no plano das abstrações. (FARIAS; ROSENVALD, 2015, p. 282).

Com isso, percebe-se que sem deixar de lado os direitos privativos do proprietário (uso, gozo e disposição), a função social da propriedade deve existir conciliando a finalidade do imóvel ao interesse social sem a eliminação do direito privado do bem que lhe 
assegure as faculdades de uso, gozo e disposição. A propriedade só será legítima se cumprida sua função social, é uma condição que determina o uso do bem em favor da coletividade, e não apenas de seu titular, e opera em relação a todas as formas de propriedade. Em qualquer caso, a propriedade constitucionalmente tutelada, em consonância com o art. $5^{\circ}$, será apenas aquela que revela o adimplemento de sua função social. (FARIAS; ROSENVALD, 2015, p. 252)

A Constituição Federal decreta limitações ao não cumprimento total do direito de propriedade, seja ela urbana ou rural. A função social da propriedade urbana, tratada no artigo 182, define:

Art. 182. A política de desenvolvimento urbano, executada pelo Poder Público municipal, conforme diretrizes gerais fixadas em lei, tem por objetivo ordenar o pleno desenvolvimento das funções sociais da cidade e garantir o bem- estar de seus habitantes. $\S 2^{\circ}$ - A propriedade urbana cumpre sua função social quando atende às exigências fundamentais de ordenação da cidade expressas no plano diretor. $\$ 3^{\circ} \mathrm{As}$ desapropriações de imóveis urbanos serão feitas com prévia e justa indenização em dinheiro.

A Constituição prevê que o Poder Público municipal deve executar a política de desenvolvimento urbano conforme diretrizes gerais fixadas no plano diretor, que contém os instrumentos que cabem ao ente público a progressividade do imposto sobre a propriedade territorial urbana, e a desapropriação de imóveis urbanos deve ser feita com prévia e justa indenização em dinheiro. (MENDES, 2012, p. 166). O imóvel rural, por sua vez, nos termos do artigo 186, exerce sua função social quando:

\footnotetext{
Art. 186. A função social é cumprida quando a propriedade rural atende, simultaneamente, segundo critérios e graus de exigência estabelecidos em lei, aos seguintes requisitos: I - aproveitamento racional e adequado; II - utilização adequada dos recursos naturais disponíveis e preservação do meio ambiente; III - observância das disposições que regulam as relações de trabalho; IV - exploração que favoreça o bem-estar dos proprietários e dos trabalhadores."
}

O imóvel rural não cumpridor de sua função social também poderá sofrer imposto territorial rural progressivo no tempo. A Constituição prevê a desapropriação em casos de necessidade ou de utilidade pública ou por interesse social, mediante prévia e justa indenização em dinheiro, de acordo com art. $5^{\circ}$, XXIV, ressalvados os casos nela previstos desapropriação de imóvel rural de interesse para a reforma agrária. (MENDES, 2012, p. 141). Tendo em vista o interesse social que embasa a desapropriação para fins de reforma agrária, reconheceu o constituinte que não serão expropriáveis a pequena e a média propriedades assim definidas em lei, desde que, também, o seu proprietário não possua outra - e a propriedade produtiva (MENDES, p. 171). O artigo 185 da Constituição Federal prescreve: 
Art. 185. São insuscetíveis de desapropriação para fins de reforma agrária: I - a pequena e média propriedade rural, assim definida em lei, desde que seu proprietário não possua outra; II - a propriedade produtiva. Parágrafo único. A lei garantirá tratamento especial à propriedade produtiva e fixará normas para o cumprimento dos requisitos relativos a sua função social.

À vista do exposto, Locke enxergava na propriedade um direito natural do indivíduo, sendo anterior à sociedade, e que não pode ser violado pelo Estado. O homem era naturalmente livre e proprietário de sua pessoa e de seu trabalho, ao incorporar seu trabalho à matéria bruta que se encontrava em estado natural o homem tornava-a sua propriedade privada, estabelecendo sobre ela um direito. O trabalho era, pois, na concepção de Locke, o fundamento originário da propriedade. Contudo, a terra da propriedade não poderiam ficar impróprios, significaria que estaria lesando e desperdiçando a reserva comum, ao passo que os frutos se estragariam de forma inútil consigo. Assim como no Ordenamento jurídico Brasileiro, a propriedade precisa atender sua função social, de caráter socializante e de interesse coletivo. A propriedade encontra-se como um direito fundamental e como princípio da ordem econômica.

\section{CONSIDERAÇÕES FINAIS}

Como apresentado neste trabalho, a propriedade privada sob a teoria de John Locke foi analisada em conformidade com o Ordenamento Jurídico, tendo em vista que a Constituição protege a propriedade como direito fundamental. Nesse sentido, explorou-se, de forma ampla, a visão do jus naturalista e, posteriormente, comparou-se com a realidade brasileira, principalmente no tocante à função social da propriedade.

Inicialmente, foi observado que Locke defendia o Estado Civil, uma vez que, sem ele, a insegurança do estado de natureza colocaria em risco a proteção da propriedade, sendo um direito natural que deveria ter sua proteção assegurada pelo Estado. Em seguida, foi abordado que, para a proteção desse direito, é necessária uma abdicação parcial dos direitos individuais para que o Estado possa agir em função dos cidadãos, denominada contrato social. A partir disso, a propriedade passa a ser responsabilidade do Estado, tendo que ser defendida por ele. Desse modo, é analisada a importância desse processo, no qual, ocorre um consenso da sociedade que o Estado tem que monitorar os cidadãos, para que haja a melhor efetividade na proteção de seus direitos. 
No que se refere à parte de função social, Locke aponta que a propriedade para pertencer ao homem, dependia da sua capacidade de transformar a natureza pelo trabalho, de modo que a terra deveria ter produtividade e que não prejudicasse o coletivo. Logo após, é explanado que, de maneira semelhante ocorre com o Ordenamento, que resguarda a função social da propriedade, de modo que só será legítima se atender a sua função, a atribuindo como princípio da ordem econômica. À vista disso, percebe-se uma relação entre a função social defendida pelo Ordenamento e o modo que a legitimação da propriedade ocorre sob a ótica de John Locke Nos dois casos, a propriedade precisa atender condições para ser validada.

Verificou-se, ainda, que apesar de Locke enxergar a propriedade como um direito natural de origem divina, de certa forma, esse direito, sendo inerente ao homem, é exercido por meio do direito fundamental, já que, são reconhecidos e positivados na esfera do direito constitucional positivo do Estado. Com isso, a propriedade, assim como todo e qualquer direito, é relativa, cedendo e moldando à outros direitos fundamentais. Diante de todo exposto, uma das grandes contribuições de Locke foi apresentar e legitimar a propriedade por meio da importância do trabalho e da sua produtividade, sendo qualificada, atualmente por meio da Constituição, pela função social.

\section{REFERÊNCIAS}

BARROS, Felipe Maciel Pinheiro. Regulação fundiária e direito à moradia: instrumentos jurídicos e o papel dos municípios. Curitiba: Juruá, 2014

BITTAR, Eduardo Carlos Bianca. Curso de filosofia política. 2. ed. São Paulo: Atlas, 2005

BRASIL. Constituição de República Federativa do Brasil, 1988.

DIMOULIS, Dimitri. MARTINS, Leonardo. Teoria geral dos direitos fundamentais. 5. ed. São Paulo: Atlas, 2014

GAGLIANO, Pablo Stolze, FILHO, Rodolfo Pamplona. Manual de direito civil. São Paulo: Saraiva, 2017

GONÇALVES, Carlos Roberto. Direito civil brasileiro: direito das coisas. 12. ed. São Paulo: Saraiva, 2017 
FARIAS, Cristiano Chaves de, ROSENVALD, Nelson. Curso de direito civil: reais. 10.ed. São Paulo: Atlas, 2015

LOCKE, John. Segundo tratado sobre o governo civil. Trad. de Magda Lopes e Marisa Lobo da Costa. Petrópolis: Vozes, 1994

MALUF, Sahid. Teoria geral do Estado. 31. ed. São Paulo: Saraiva, 2013

MENDES, Gilmar Ferreira. Direitos fundamentais e controle de constitucionalidade. $4^{\circ}$. ed. São Paulo: Saraiva, 2012.

VENOSA, Ś́lvio de Salvo. Direito civil: reais. 17. ed. São Paulo: Atlas, 2017

WEFFORT, Francisco C. Os clássicos da política: Maquiavel, Hobbes, Locke, Montesquieu, Rosseau, 'O federalista'. São Paulo: Ática, 2006

\title{
JOHN LOCKE'S THEORY AND BRAZILIAN LAW: A PARALLEL FOR THE PROPERTY SOCIAL FUNCTION
}

\begin{abstract}
The right to property is part of a historical process of construction and for the naturalist John Locke, property can be visualized as a natural right of divine origin that cannot be violated. Now, this right counts with restrictions and it is protected as a fundamental right in the constitutional order, and its social function guaranteed in the Federal Constitution. This study presents the private property from the perspective of John Lock, pondering his understanding with the mechanisms of protection in the legal order, especially the social function legitimized by them. The analyzes were developed from the exploratory qualitative research bias comparing theories with legal documents and using the inductive method. It understands that Locke's theory and the brazilian legal system have similarity to the right to use property, for Locke property must be legitimized by the work of man, being productive and not damaging the collective, prescribed in the order as attending the social function. In the end, it concludes that the ideas supported by Locke are part of a historical evolution that helped the diffusion of the studies that the property is an inherent right to the
\end{abstract}


man and that must be protected by the State, since the brazilian legal system recognizes the property, its function social and importance.

Keywords: John Locke. Civil state. Right to property. Property social function. 